\title{
TIMI Coronary Thrombus Grade 2
}

National Cancer Institute

\section{Source}

National Cancer Institute. TIMI Coronary Thrombus Grade 2. NCI Thesaurus. Code C119584.

Small size definite thrombus, with greatest dimensions less than or equal to $1 / 2$ vessel diameter. (Gibson, C. M., de Lemos, J. A., Murphy, S. A., Marble, S. J., McCabe, C. H., Cannon, C. P., Antman, E. M., Braunwald, E. Combination therapy with abciximab reduces ang iog raphically evident thrombus in acute myocardial infarction: a TIMI 14 substudy Circulation. 2001;103(21):2550-4.) 